\title{
Induction of ovulation with pulsatile luteinising hormone releasing hormone
}

\author{
P MASON, J ADAMS, D V MORRIS, M TUCKER, J PRICE, Z VOULGARIS, Z M VAN DER SPUY, \\ I SUTHERLAND, G R CHAMBERS, S WHITE, M J WHEELER, H S JACOBS
}

\begin{abstract}
Ovulation was successfully induced with luteinising hormone releasing hormone in 28 women with hypothalamic amenorrhoea who had failed to respond to treatment with clomiphene. Luteinising hormone releasing hormone was administered in a pulsatile manner with miniaturised automatic infusion systems. The rate of ovarian follicular maturation, as monitored by serial pelvic ultrasonography, was similar to that observed in spontaneous cycles. Endocrine assessment by serial measurement of gonadotrophin, oestradiol, and progesterone concentrations showed hormone concentrations to be within the normal range. Intravenous treatment was required in only two patients, the remainder
\end{abstract}

Department of Gynaecology, St Mary's Hospital, London W2
P MASON, MRCOG, FRCS, senior registrar

Cobbold Laboratories, Middlesex Hospital, London W1N 8AA

J ADAMS, SRN, DCR, ultrasonographer

D V MORRIS, MRCP, senior registrar in medicine

$M$ TUCKER, MRCOG, MB, senior registrar

J PRICE, MB, CHB, research registrar

$Z$ VOULGARIS, $M B$, research registrar

Z M VAN DER SPUY, MRCOG, MB, research lecturer

H S JACOBS, FRCP, MD, professor of gynaecological endocrinology

National Institute for Medical Research, Mill Hill, London NW7 1AA I SUTHERLAND, BSC, PHD, engineer

G R CHAMBERS, BSC, engineer

$S$ WHITE, BSC, engineer Department of Chemical Pathology, St Thomas's Hospital, London
SE1

M J WHEELER, BSC, PHD, consultant biochemical pathologist

Correspondence to: Mr Peter Mason, Cobbold Laboratories, Middlesex Hospital, London WIN 8AA. responding satisfactorily to subcutaneous infusion. All patients conceived within six cycles of treatment, and only one multiple pregnancy occurred.

\section{Introduction}

Hypogonadotrophic hypogonadism is an important cause of anovulatory infertility. ${ }^{1}$ Though many patients with this disorder respond to antioestrogen clomiphene citrate treatment, an appreciable proportion require treatment with human menopausal gonadotrophin and human chorionic gonadotrophin. Despite close biochemical and ultrasonic supervision treatment with gonadotrophins is associated with a major risk of multiple conception $(20 \%)$ and ovarian hyperstimulation $(3 \%){ }^{2}$

Normal secretion of gonadotrophin depends on the pulsatile release of luteinising hormone releasing hormone by the hypothalamus. $^{3-5}$ The artificial synthesis of this hormone has led to attempts to use it to directly stimulate release of gonadotrophins in patients with hypogonadotrophic hypogonadism. Although Kastin et al reported the first conception after treatment with luteinising hormone releasing hormone in $1971,{ }^{6}$ high dose injections of luteinising hormone releasing hormone given at infrequent intervals have not proved a reliable form of treatment for inducing ovulation in patients with hypogonadotrophic hypogonadism. ${ }^{78}$ Leyendecker et al were the first to show the effectiveness of high frequency pulsatile treatment with luteinising hormone releasing hormone in stimulating ovulation in women and have reported the successful treatment of patients with hypothalamic amenorrhoea. ${ }^{9}$ Their findings have been confirmed by other investigators. ${ }^{1011}$

Results of initial studies suggested that subcutaneous administration of luteinising hormone releasing hormone might not be appropriate, ${ }^{12}$ and Leyendecker et al relied on the intravenous route for infusion..$^{13} 14$ Other workers, however, have claimed that subcutaneous infusion is effective. ${ }^{15} 16$ The incidence of multiple pregnancy after pulsatile treatment with luteinising hormone releasing hormone also seems to be considerably lower than that after gonadotrophin injections. As intravenous infusion can present problems and is potentially hazardous over prolonged periods we undertook a study to 
investigate the efficacy of subcutaneous pulsatile treatment with luteinising hormone releasing hormone in a group of 28 patients with hypothalamic amenorrhoea of differing aetiologies. We report their response in terms of both ovulation and conception.

\section{Patients and methods}

We treated 28 women with amenorrhoea and infertility. All had been investigated according to the protocol of Hull et al. ${ }^{1}$ None had experienced vaginal bleeding in response to challenge with progestogen or had ovulated after treatment with clomiphene citrate. ${ }^{17}$ In all

Dosage of luteinising hormone releasing hormone (LHRH) given in each cycle

\begin{tabular}{ccc}
\hline No of cycles & Dose/pulse $(\mu \mathrm{g})$ & $\begin{array}{c}\text { Total daily dose } \\
(\mu \mathrm{g})\end{array}$ \\
\hline 4 & 10 & 160 \\
81 & 15 & 240 \\
3 & 20 & 380 \\
1 & 25 & 400 \\
\hline
\end{tabular}

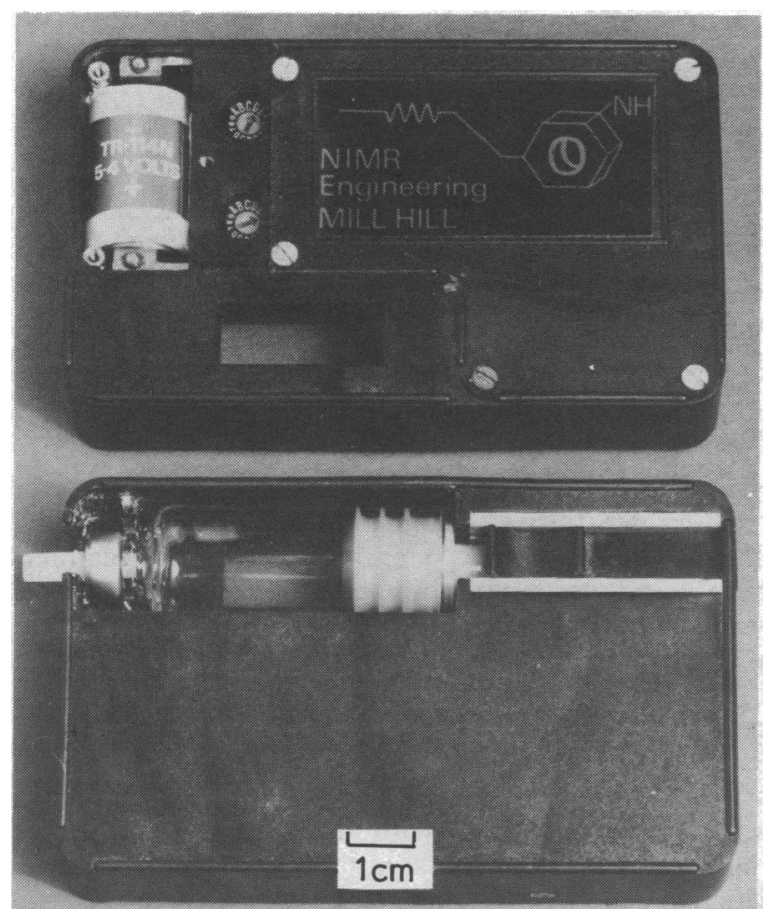

FIG 1-Automatic infusion pump for administration of luteinising releasing hormone. When in use a plastic flange covers battery and two micro switches, which control duration and interval of pulse.

patients laparoscopy yielded normal results and a dye test for tubal patency was positive; all patients were married to men in whom analysis of semen yielded normal results.

Six patients (mean (SD) age $27 \cdot 3(6 \cdot 5)$ years) had primary amenorrhoea, which was associated with anosmia in five (18); in the sixth patient computed tomography showed an empty sella but pituitary function tests gave normal results apart from evidence of hypogonadotrophic hypogonadism. Twenty two patients (mean age $32 \cdot 3$ $(6 \cdot 0)$ years) had secondary amenorrhoea, its duration ranging from nine to 216 months (mean $50(8)$ ). One patient with hypothalamic panhypopituitarism had a history of tuberculous meningitis followed by a tuberculoma of the pituitary stalk and at the time of treatment with luteinising hormone releasing hormone was receiving intranasal desmopressin and oral thyroxine and prednisolone. Another patient had been successfully treated for a medulloblastoma arising in the region of the fourth ventricle. The remaining patients with secondary amenorrhoea had weight related amenorrhoea (six cases) ${ }^{\mathbf{1 9}}$ or undiagnosed "functional" amenorrhoea (14 cases) associated with normal serum prolactin, gonadotrophin, and thyroid hormone concentrations. Four women with primary and three with secondary amenorrhoea had been treated previously with injections of human menopausal gonadotrophin and chorionic gonadotrophin, but none had conceived.

Luteinising hormone releasing hormone $100 \mathrm{mg} / 1$ (LH-RH: Hoechst) was injected at intervals of 90 minutes in doses ranging from 10 to $25 \mu \mathrm{g} /$ pulse. We found that few patients ovulated with doses of less than $15 \mu \mathrm{g} / \mathrm{pulse}$, and the table shows that in most cycles the total daily dose was $240 \mu \mathrm{g}$ administered in 16 injections of $15 \mu \mathrm{g}$ each. The frequency of injections was based on that reported for spontaneous pulses of luteinising hormone in normal women during the follicular phase of the ovulation cycle. ${ }^{2021}$

The injections were administered with a miniaturised automatic pump specifically designed for this purpose at the National Institute for Medical Research, Mill Hill. This pump is based on a previously described direct drive insulin pump. ${ }^{22}$ In all patients treatment was initially given by the subcutaneous route with a 27 gauge infusion set (Autosyringe Asiv 27/061, Travenol). The patients were encouraged to change the site of infusion every three days and experienced no difficulty with this. Two patients failed to respond to subcutaneous treatment and were therefore treated intravenously. Heparin 500 was added to the solution of luteinising hormone releasing hormone $(150 \mathrm{IU} / \mathrm{ml})$ in these two patients, and the solution was infused through a fine cannula (Portex 200/300/010) inserted into a forearm vein.

Initially, because of a shortage of infusion devices, the pump was removed once ovulation was confirmed and the corpus luteum supported with three injections of human chorionic gonadotrophin (2500 IU intramuscularly on days 17, 21, and 25). After the first 16 cycles of treatment pulses of luteinising hormone releasing hormone were continued throughout the luteal phase of the cycle until conception was confirmed.

\section{MONITORING}

Ultrasonography-The response to treatment was assessed on alternate days by serial pelvic ultrasonic imaging with an Emisonic 3201 scanner equipped with a $3.5 \mathrm{mHz}$ long focused transducer. The maximum diameter of the dominant ovarian follicle was recorded and the uterine size assessed planimetrically from the maximum uterine cross sectional area and the uterine length. Ovulation was considered to have occurred in the interval between visualisation of a mature follicle on one scan and the appearance of a ruptured follicle or early corpus luteum at the next examination. Pregnancy was confirmed ultrasonically and by measurement of serum chorionic gonadotrophin concentrations. If menstruation occurred treatment with luteinising hormone releasing hormone was continued uninterrupted into the subsequent cycle.

Endocrine assessment-Serial samples were taken throughout the induced cycles for measurement of circulating concentrations of luteinising hormone (Medical Research Council 68/40 standard) and follicle stimulating hormone (Medical Research Council 69/104 standard). ${ }^{23}$ Oestradiol $17 \beta$ was measured with Steranti kits (variation within assays $6 \%$, between assays $10 \%$ ) and progesterone by standard radioimmunoassay techniques. All samples relating to an individual cycle were measured in the same assay.

\section{Results}

INVESTIGATIONS BEFORE TREATMENT

Luteinising hormone and follicle stimulating hormone concentrations were measured before a $100 \mu \mathrm{g}$ luteinising hormone releasing hormone diagnostic test in all patients and at 20 minute intervals afterwards in 22 patients. Figure 2 shows the widely varying results in the 22 patients. Serum thyroid stimulating hormone and prolactin concentrations were measured in response to an intravenous injection of $200 \mu \mathrm{g}$ of thyrotrophin releasing hormone and were normal in all except the patient with hypothalamic hypopituitarism due to a tuberculoma. All patients underwent ultrasonic assessment of the pelvis before treatment, and none showed any evidence of spontaneous ovarian follicular development or of cystic ovaries. ${ }^{24}$

\section{FERTILITY}

Eighty three cycles were induced by subcutaneous injection and six by intravenous injection. In three of the subcutaneously induced cycles ovulation did not occur, and the patients were then given 
intravenous luteinising hormone releasing hormone. Conception occurred in 30 of the 86 cycles in which ovulation was confirmed; two patients conceived twice. All 28 patients conceived within six cycles of treatment, 19 within three months. Eight patients suffered spontaneous abortions, all in the first trimester; two of these patients received further courses of treatment and conceived again. In one of the patients given human chorionic gonadotrophin for luteal support smaller secondary and tertiary follicles were seen to rupture and undergo luteinisation, and a triplet pregnancy ensued. Subsequently, luteal support was provided by continued infusion of luteinising hormone releasing hormone, and no further multiple pregnancies occurred.

By the end of the study 13 patients were pregnant and nine patients conceived during their first cycles of treatment despite uterine cross sectional areas before treatment of only $4.8 \mathrm{~cm}^{2}$ and $5.7 \mathrm{~cm}^{2}$ with corresponding uterine lengths of only $4 \cdot 2 \mathrm{~cm}$ and $4 \cdot 8 \mathrm{~cm}$, respectively. In both cases pregnancy progressed uneventfully.

\section{ENDOCRINE FINDINGS}

Figure 3 shows the changing concentrations of gonadotrophins in each woman during her first ovulation cycle (excluding cycles in which conception occurred) in which the corpus luteum was supported by pulsatile infusion of luteinising hormone releasing hormone. The patterns of gonadotrophin concentrations were similar to those found

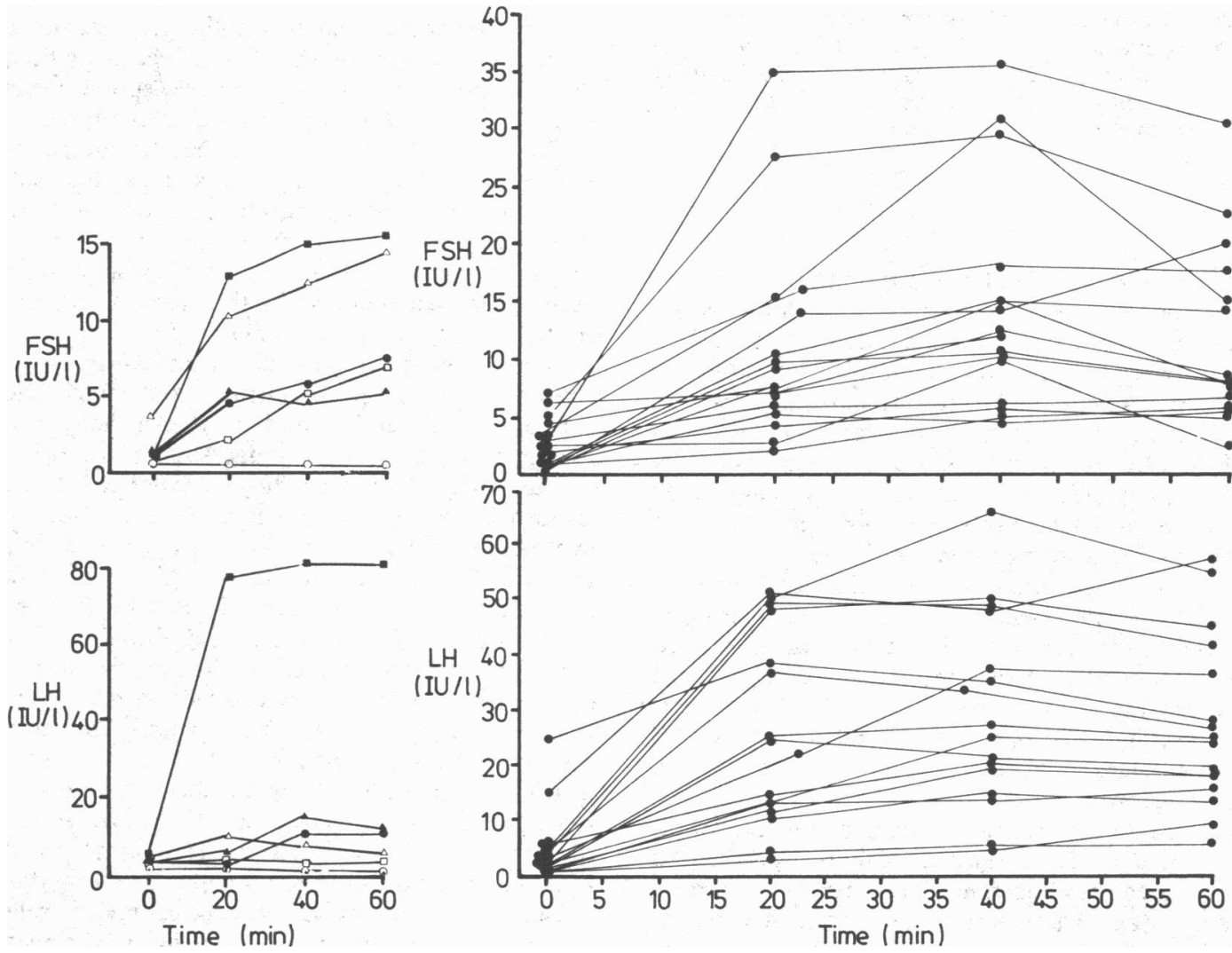

FIG 2-Concentrations of follicle stimulating hormone (FSH) and luteinising hormone (LH) in response to a diagnostic test with $100 \mu \mathrm{g}$ luteinising hormone releasing hormone in (left) six women with primary amenorrhoea and in (right) 16 women with secondary amenorrhoea.

had already given birth. The weights of the infants were within the 10 th and 90 th centiles of weight for gestational age. Eight of the infants were born after 38-40 weeks' gestation; in the triplet pregnancy labour occurred at 32 weeks' gestation.

\section{ULTRASONIC FINDINGS}

Sequential ovarian ultrasonography showed changes suggesting the evolution and rupture of a dominant follicle with subsequent development of a corpus luteum in 86 cycles, and ovulation was confirmed by subsequent increases in the serum progesterone concentration. The rate of increase in the diameter of the dominant follicle was 1.91 (SEM 0.9) $\mathrm{mm} /$ day. The mean diameter of the follicle at presumed time of ovulation was $2 \cdot 15(1 \cdot 4) \mathrm{mm}$. No significant difference was noted in the pattern of follicular growth between cycles in which conception occurred and those in which it did not (see fig 3).

In the patients with primary amenorrhoea the uterine cross sectional area before treatment was significantly smaller $\left(7.5(\right.$ SEM 1.7$) \mathrm{cm}^{2}$; $\mathrm{n}=6)$ than that in the patients with secondary amenorrhoea (21 (3) $\left.\mathrm{cm}^{2} ; \mathrm{n}=22\right)(\mathrm{p}<0.01)$. In those cycles in which ovulation occurred, once a dominant follicle had been selected the uterus grew at a similar rate in both groups. Anovulation was reflected by lack of uterine growth. Initial uterine size did not influence fertility; two patients
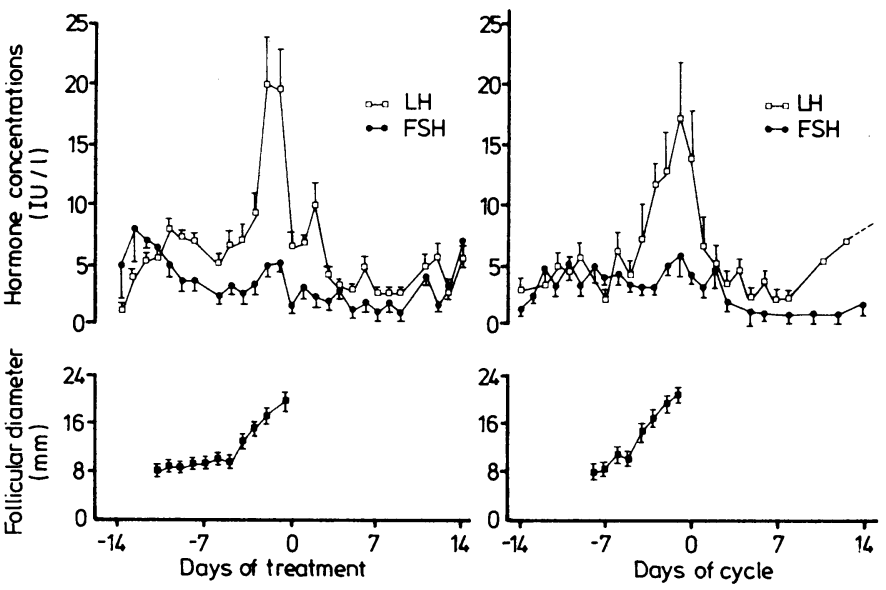

FIG 3-Mean (SEM) serum concentrations of luteinising hormone (LH) and follicle stimulating hormone (FSH) and follicular diameters in (left) 20 ovulatory cycles in which conception did not occur and (right) 25 cycles in which conception occurred. Apparent increase in luteinising hormone at end of conception cycles is caused by chorionic gonadotrophin cross reacting in luteinising hormone assay. Day 0 is day of presumed ovulation. 
in spontaneous ovarian cycles. Figure 3 also shows serum gonadotrophin concentrations in 25 cycles in which conception occurred. There was no difference in gonadotrophin concentrations before ovulation between cycles in which conception occurred and those in which it did not, although the pregnancies were reflected by an increase in concentrations of "luteinising hormone" (human chorionic gonadotrophin, in fact) in the luteal phase. In one patient (the patient with a history of a tuberculoma of the pituitary stalk) induction of ovulation and conception occurred in the first cycle of treatment despite hyperprolactinaemia (initial serum prolactin concentration $1756 \mathrm{mU} / \mathrm{l}$ ).

\section{COMPLICATIONS OF TREATMENT}

No problems resulted from the long term use of subcutaneous infusion cannulas, but in one patient treated intravenously phlebitis occurred at the site of infusion. This resolved with oral antibiotic treatment, and no organism was cultured from the blood or the cannula. Pump failures occurred on two occasions in the follicular phase and once in the luteal phase but were remedied within 24 hours and did not seem to impair the effect of treatment.

\section{Discussion}

Our study confirms the efficacy of low dose pulsatile infusion of luteinising hormone releasing hormone in anovulatory infertility resistant to treatment with clomiphene. The introduction of this technique has depended on the creation of reliable automatic portable devices for infusion. Several are currently available, and we are preparing a report of our own assessment of them. In the present study we used specially designed pumps (fig 1), which had the advantage of being small, robust, highly reliable, and acceptable to all our patients.

The success of this form of treatment relies on the physiological characteristics of luteinising hormone releasing hormone. The hormone increases the responsiveness of the pituitary gonadotrope to further stimulation with the hormone, and this self priming effect occurs only when stimulation is in the form of discrete pulses. When the pulse frequency rises above a critical value pituitary sensitivity falls, possibly as a result of a loss of luteinising hormone releasing hormone receptors ${ }^{25}$ or possibly because of a postreceptor effect. ${ }^{26}$

Our results confirm that, in women with hypogonadotrophic hypogonadism, when a constant dose of luteinising hormone releasing hormone is given at a constant pulse interval the pattern of endocrine changes (fig 3 ) is the same as that seen in spontaneous ovulation cycles. This strongly suggests that the hormone has only a permissive role in the neuroendocrine control of ovulation and that the factors controlling positive and negative feedback operate at the pituitary level.

Patients with clomiphene resistant anovulatory infertility and normal prolactinaemia usually require combined treatment with human menopausal gonadotrophin and chorionic gonadotrophin, and this treatment even when closely supervised is associated with a $20 \%$ or more risk of multiple pregnancy. ${ }^{27}$ In the present study multiple ovulation developed in only one patient. This woman was one of those given human chorionic gonadotrophin within 24 hours of ultrasonic diagnosis of ovulation of a dominant follicle. These data suggest that the major factor determining the low incidence of multiple conception seen in this study, and in spontaneous pregnancies, is the control provided by intact pituitary feedback mechanisms. The low incidence of multiple conceptions reported here together with hormone concentrations during induced cycles that are within the normal range for spontaneous cycles (fig 3) strongly support our policy of discarding endocrine surveillance in favour of ultrasonic monitoring of ovarian follicular development. (It is technically simple to assess changes in uterine size and thereby provide clinicians with a biological assay of follicular secretion of oestrogen.)

As almost all multiple conceptions reported in association with treatment with luteinising hormone secreting hormone have occurred in cycles in which chorionic gonadotrophin was used to support the corpus luteum ${ }^{1328}$ we have now stopped its use.
As well as avoiding this problem, continuing the infusion of luteinising hormone releasing hormone also offers effective support of the corpus luteum and permits early diagnosis of pregnancy by measurement of serum chorionic gonadotrophin concentrations.

Previous studies have suggested that a wide range of doses of luteinising hormone releasing hormone may be used, with adjustments according to the theoretical severity of the hypogonadotrophic hypogonadism. ${ }^{13}$ Despite the wide range of responses of luteinising hormone and follicle stimulating hormone in the diagnostic luteinising hormone releasing hormone test (fig 2), we did not find these adjustments to be necessary, and all the patients reported on here responded to a standard dose of $15 \mu \mathrm{g} / \mathrm{pulse}$. The pulse frequency of 90 minutes was selected from a study of normal ovulatory cycles ${ }^{21}$ and was found to be effective in both follicular and luteal phases. We are currently investigating the effect of reducing the pulse frequency during the luteal phase because spontaneous pulsatility of luteinising hormone is decreased at this time.

The route of infusion has been the subject of some dispute. Reid et al suggested that subcutaneous administration produces disordered follicular maturation. ${ }^{12}$ In separate studies we found that poor follicular progression occurs only with suboptimal doses of luteinising hormone releasing hormone but can be reversed by an increase in the dose. Using the subcutaneous route we failed to induce ovulation in only two patients, although in these women intravenous treatment at the same dosage was effective. We therefore consider that subcutaneous infusion is simple and safe and should be used initially in all patients with hypogonadotrophic hypogonadism.

Our study confirms the importance of skilled ultrasonic monitoring of ovarian and uterine changes during induced cycles. Such monitoring allowed us to stop endocrine surveillance during treatment, and we have also found ultrasonic assessment before treatment to be critical in selecting patients for treatment. Women showing multiple cystic ovarian changes -either those associated with the classical Stein-Leventhal syndrome or megalocystic changes ${ }^{24}$-do not in our experience respond reliably to treatment with subcutaneous luteinising hormone releasing hormone. Though women with megalocystic ovaries can be successfully treated with intravenous luteinising hormone releasing hormone, those with polycystic ovarian disease respond unsatisfactorily to treatment with this hormone.

In conclusion, our results show that low dose subcutaneous pulsatile infusion of luteinising hormone releasing hormone offers an appreciable advance in the treatment of hypothalamic amenorrhoea. When used alone the hormone reliably produces singleton pregnancies and allows clinicians to stop using expensive and complicated biochemical monitoring. In the patients reported on here its use restored normal fertility.

This study was made possible through financial support by the Birthright Trust. M T was supported by the Berkeley Fellowship. We thank Dr P M Magill of Hoechst UK Ltd for generous supplies of luteinising hormone releasing hormone. We are grateful for the guidance and support of Mr D Rothwell, head of the engineering department at the National Institute for Medical Research, and to the workshop staff for constructing the pumps.

\section{References}

${ }^{1}$ Hull MGR, Savage PE, Jacobs HS. Investigation and treatment of amenorrhoea resulting in normal fertility. Br Med f 1979;i:1257-61.

2 Lunenfeld B, Insler V. Diagnosis and treatment of functional infertility. Berlin: Gross Verlag, 1978.

3 Knobil E. Patterns of hypophysiotropic signals and gonadotrophin secretion in the rhesus monkey. Biol Reprod 1981 ;24:44-9.

- Hausler A, Wildt L, Marshall G, Plant TM, Belchetz PE, Knobil E. Modulation of pituitary gonadotrophin secretion by frequency of GnRH input. Fed Proc 1979;38:1107-12.

5 Schally AV. Aspects of hypothalamic regulation of the pituitary gland. Science 1978;202:18-28.

6 Kastin AJ, Zarate A, Midgley AR, Canales ES, Schally AV. Ovulation 
confirmed by pregnancy after infusion of porcine LH-RH. $₹$ Clin Endocrinol Metab $1971 ; 33: 980-2$.

${ }^{7}$ Nillius SJ. Gonadotrophin-releasing hormone for induction of ovulation in women. In: Hafez ESE, ed. Human ovulation. Amsterdam: North Holland, 1979:385-404.

" Mortimer CH, Besser GM, McNeilly AS. Uses. In: Motta M, Crosignani PG, Martini L, eds. Hypothalamic hormones, chemistry, physiology, pharmacology and clinical uses. New York: Academic Press, 1975:325-35.

${ }^{9}$ Leyendecker G, Wildt L, Hansmann M. Pregnancies following chronic intermittent (pulsatile) administration of $\mathrm{Gn}-\mathrm{RH}$ by means of a portable pump ("Zyklomat")-a new approach to the treatment of infertility in hypothalamic amenorrhoea. 7 Clin Endocrinol Metab 1980;51:1214-6.

10 Shoemaker J, Simons AHM, van Osnabrugge GJC, Lugtenburg C, van Kessel $\mathrm{H}$. Pregnancy after prolonged pulsatile administration of LHRH in a patient with clomiphene resistant secondary amenorrhoea. $\mathcal{F}$ Clin Endocrinol Metab $1981 ; 52: 882-5$.

"Crowley WF Jr, McArthur JW. Simulation of the normal menstrual cycle in Kallman's syndrome by pulsatile administration of luteinizing hormone-releasing hormone. $\mathcal{F}$ Clin Endocrinol Metab 1980;51:173-5.

12 Reid RL, Leopold GR, Yen SSC. Induction of ovulation and pregnancy with pulsatile luteinizing hormone releasing factor: dosage and mode of delivery. Fertil Steril $1981 ; 36: 553-9$.

${ }^{13}$ Leyendecker G, Struve T, Plotz EJ. Induction of ovulation with chronic intermittent (pulsatile) administration of LH-RH in women with hypothalamic and hyperprolactinemic amenorrhea. Arch Gynecol 1980;229: 177-90.

${ }^{14}$ Leyendecker G, Wildt L, Hansmann M. Pregnancies following chronic intermittent (pulsatile) administration of $\mathrm{Gn}-\mathrm{RH}$ by means of a portable pump-a new approach to treatment of infertility in hypothalamic amenorrhoea. F Clin Endocrinol Metab 1980;51:1214-26.

15 Skarin G, Nillius SJ, Wide L. Pulsatile low dose LHRH treatment for induction of follicular maturation and ovulation in women with amenorrhoea. Acta Endocrinol 1982;101:78-86.

${ }^{16}$ Keogh EJ, Mallal SA, Giles PFH, Evans DV. Ovulation induction with intermittent subcutaneous LHRH. Lancet 1981 ; : 147.
17 Hull MGR, Knuth UA, Murray MAF, Jacobs HS. The practical value of the progestogen challenge test, serum oestradiol estimation or clinical examination in assessment of the oestrogen state and response to clomiphene in amenorrhoea. Br F Obstet Gynaecol 1979;86:799-805.

${ }^{18}$ Kallmann FJ, Schonfeld WA, Barrera SE. Genetic aspects of primary eunuchoidism. Am 7 Ment Defic 1944;48:203-36.

19 Knuth UA, Hull MGR, Jacobs HS. Amenorrhoea and loss of weight. $B r \mathcal{F}$ Obstet Gynaecol 1977;84:801-7.

20 Yen SSC, Tsai CC, Naftolin F, van den Berg G, Ajabor L. Pulsatile patterns of gonadotrophin release in subjects with and without ovarian function. $\mathcal{f}$ Clin Endocrinol Metab 1972;34:671-5.

21 Backstrom CT, McNeilly AS, Leask RM, Baird DT. Pulsatile secretion of $\mathrm{LH}, \mathrm{FSH}$, prolactin, oestradiol and progesterone during the human menstrual cycle. Clin Endocrinol 1982;17:29-37.

22 Rothwell D, Sutherland IA, Pickup JC. A new miniature, open-loop, extracorporeal insulin infusion pump. 7 Biomed Eng 1983;5:177-272.

23 Toone BK, Wheeler M, Fenwick PBC. Sex hormone changes in male epileptics. Clin Endocrinol 1980;12:391-5.

24 Tucker M, Mason WP, Adams J, Jacobs HS. Multicystic enlarged ovaries -a new syndrome? In: Royal College of Obstetricians and Gynaecologists, ed. Programme of 23rd British congress of obstetricians and gynaecologists. Birmingham: Royal College of Obstetricians and Gynaecologists, 1983:1143.

${ }^{25} \mathrm{Knobil} \mathrm{E}$. The neuroendocrine control of the menstrual cycle. Recent Prog Horm Res 1980;36:53-88.

${ }^{26}$ Smith MA, Perrin MH, Vale WW. Desensitization of cultured pituitary cells to gonadotropin-releasing hormone: Evidence for a post-receptor mechanism. Mol Cell Endocrinol 1983;30:85-96.

27 Gemzell CA. Induction of ovulation with human gonadotrophins. $\mathcal{f}$ Reprod Med 1977;18:155-8.

28 Bogchelman D, Lappöhn RE, Janssens J. Triplet pregnancy after pulsatile administration of gonadotrophin releasing hormone. Lancet $1982 ; \mathrm{ii}: 45-6$.

(Accepted 24 November 1983)

\title{
Role of exercise testing early after myocardial infarction in identifying candidates for coronary surgery
}

\author{
K JENNINGS，D S REID，T HAWKINS，D J JULIAN
}

\begin{abstract}
It has been suggested that ST depression in lead V5 or equivalent on early exercise testing after acute myocardial infarction predicts a high risk of death. To evaluate exercise testing and radionuclide ventriculography in this context 103 consecutive patients with myocardial infarction who were able to undertake a limited exercise test before discharge from hospital were exercised and underwent gated blood pool scanning. No serious complications resulted from exercise testing. Twenty nine patients developed ST depression in lead V5, 19 had exertional hypotension, 31 developed a heart rate of $\geqslant 130$ beats/min, and 15 had complex ventricular arrhythmias. Death during the first year after discharge from hospital was associated with exertional hypotension $(p<0.001)$ and a heart rate on exercise testing of $\geqslant 130$ beats/min $(p<0.05)$; these two variables identified all nine deaths. Inability to complete the exercise protocol for any reason was also predictive of death $(\mathbf{p}<0.01)$.
\end{abstract}

Cardiology Department, Freeman Hospital, Newcastle upon Tyne NE7 7DN

K JENNINGS, MB, MRCP, senior registrar

D S REID, MB, FRCP, consultant cardiologist

D G JULIAN, MD, FRCP, professor of cardiology

Regional Medical Physics Department, Freeman Hospital

T HAWKINS, BSC, senior physicist

Correspondence to: Dr K Jennings, Royal Infirmary, Aberdeen AB9 2ZB.
Ventricular arrhythmias and ST depression in lead V5 induced by exercise were not significantly associated with an increased risk of death. The mean (SD) radionuclide ejection fraction in the patients who died was 29 (16)\% compared with 43 (11)\% in the patients who survived $(\mathbf{p}<\mathbf{0 . 0 0 1})$.

ST changes on exercise testing after myocardial infarction appear to be less predictive of later complications than haemodynamic signs, which may indicate left ventricular damage rather than ischaemia.

\section{Introduction}

The high mortality among patients in the months after myocardial infarction and the existence of treatments that may prove beneficial to some survivors but harmful to others make it necessary to identify the variables that characterise patients likely to benefit from specific forms of treatment. It has been suggested that exercise testing early after infarction may identify such variables; one study showed that ST depression in lead CM5 induced by exercise early after infarction predicted death in the following year. ${ }^{1}$ Akhras et al suggested that this ST change might be an indication for early coronary surgery because it represents hazardous but reversible ischaemia. ${ }^{2}$ If such findings were confirmed exercise testing after infarction might prove valuable in identifying patients who would benefit from early revascularisation. To evaluate the exercise test in this context we reviewed a consecutive population of patients who were able to undertake a limited exercise protocol early after infarction. 